TURIZAM

Volume 22, Issue 1

10-18 (2018)

ORIGINAL

SCIENTIFIC PAPER

\title{
Former Yugoslav National Parks are Going Social? An Exploratory Study on Facebook
}

\author{
Nataša DragovićA*, Marija CimbaljevićA ${ }^{A}$ Uglješa Stankov ${ }^{A}$, \\ Đorđije VasiljevićA, Miroslav D. VujičićA, Vanja Pavluković ${ }^{A}$ \\ Received: March 2018 | Accepted: April 2018
}

DOI: $10.5937 / 22-17511$

\begin{abstract}
Today, a large number of people use the Internet for a variety of purposes. There is a growing presence of social networks in different spheres of life. Consequently, the connection of national parks and social media has begun. In this way, the management of national parks is facilitated in general, because data from social media can be of great help. Communication with visitors of national parks, through social media, has great potential in protecting such areas, but also in providing a wealth of experience. Therefore, it is essential to constantly update and direct visitors to the official Facebook sites of national parks. In this paper, the presence and activity of national parks sites on Facebook, in Former Yugoslavia (Bosnia and Herzegovina, Croatia, FYR Macedonia, Montenegro, Serbia and Slovenia) is explored with the aim to seek for common practices, good examples or pitfalls.
\end{abstract}

Keywords: national parks, Former Yugoslavia, social networks, Facebook

\section{Introduction}

Millions of people are using social network sites (SNSs) as they serve a number of functions in online and offline life, such as information search, providing emotional and social support and creating and maintaining ties to other people (Pempek et al., 2009). Facebook has become a standard marketing channel for many organizations in the world (Stankov et al., 2018). Furthermore, characteristics of SNSs dramatically changed how travellers plan and consume travel related products. The main reason is SNSs becomes increasingly important in travel planning, during the travel, as well as in post-travel activities (Chung, Buhalis, 2008). It means that popular platforms such as Facebook, Twitter or Instagram enable visitors to share information about their trip, providing the ability to create a significant connection between destination-related information and visitors' interests (Fotis et al., 2012). At the same time, an increasing number of visitors and public are discovering protected nature directly or through their

A Univeristy of Novi Sad, Faculty of Sciences, Department of Geography, Tourism and Hotel Management; Trg Dositeja Obradovića 3, 21000 Novi Sad, Serbia

* Corresponding author: natasadragovic777@gmail.com 
friends and family on SNSs. Likes, posts or comments are new language that should be adopted by national parks (NP) managers in order to express their mission and messages in digital era.

Nowadays, having presence on Facebook, as a most used and most influential SNS, is a prerequisite for social media promotion activities. Social-media platforms allow destination managers to adopt and adjust information to a specific audience in a very cost-effective and easy way (Tham, 2013). Unlike individuals who use Profiles (webpages containing user's information) to present themselves on Facebook, companies mostly use Facebook Pages. This alternative allows businesses, brands and all types of organizations to create a free presence on Facebook and create online partnerships. Users can interact and affiliate as a fan of an organization's Page in the same way they interact with other Profiles (Cooper, 2010). Once the users become a fan of a company on Facebook, they can "like", "share", "comment". posts, actively expressing an engagement with the posting. Besides it can result in greater levels of traveler engagement, it can also increase ability of organizations or managers to effectively communicate with the public (Matloka, Buhalis, 2010). Thus, by knowing information about content visitors interact the most, how often they visit Facebook page, etc., managers can modify their communication efforts in a more effective way.

National parks (NP) and other organizational structures for environmental protection increasingly recognized growing popularity of Facebook. Through social media, it is possible to inform visitors in a simple way about the latest developments, important information related to the national park, extreme weather as well as monitoring the visits of national parks. Also, social networks carry certain risks. One of them is the presence of a large number of sites and groups on Facebook, which are not official sites of national parks, where inaccurate information on current events in national parks is shared. Hence this topic is gaining importance since it is attracting more and more academic and practitioner attention. Such process is, however, uneven in different parts of the world. This paper examines level of adopting and current practices of Facebook usage by the NPs in former Yugoslav countries (Bosnia and Herzegovina, Croatia, FYR Macedonia, Montenegro, Serbia and Slovenia),with the aim to seek for common practices, good examples or pitfalls.

In most cases, NPs can be seen as a tourist destination and consequently, parts of parks' managing structures can act as destination management organizations (DMOs). Therefore, this research proposes and adopts the use of common methodology for assessing destination management organizations Facebook Pages in order to explore the level and form of acceptance among NPs.

\section{Social media use in protected areas}

Data collected from social media is often used as an important indicator of human activities in different environments, including protected areas, where gathering information about visitors requires a lot of time and workforce. The study of Tenkanen and colleagues (2017) have showed that social media activity from Instagram, Twitter and Flickr is highly associated with NP popularity, and social media-based monthly visitation patterns match relatively well with the official visitor counts. Also, it has been established that Instagram shows better results of the visit, compared to Flickr and Twitter. Tenkanen and his associates (2017) also analysed the causes of larger or smaller visitor activities on social media. They have noticed that visitors were less likely to publish pictures from national parks when it was foggy or sour, due to poor shoot- 
ing conditions, while the activity of sharing images on social media was intensified during the spring. It is also considered that the use of social media is the highest among younger visitors. For that reason, the activity on social media has increased in certain periods of the year, e.g., in the period of school breaks and when the young population have time to visit national parks.

Some national parks in the United States have a special sector that manage social networks. One of them is the Glacier National Park. Their team has presented their data management strategy, which they receive through social networks. Since the official site of the national park has good visibility, it gives them the possibility to rely on their strategy on social media, because visitors are very active on the same. In this way, visitors quickly get information about the national park, attractions, and etc. They also consider that social networks are the easiest way to redirect visitors to the official website of Glacier National Park.

Administrators of the Glacier National Park site, on social networks, often faced the problem of inaccurate or partly inaccurate information about a national park. Therefore, it is important to pay more attention on social media, to the management of official sites and national park groups, so that visitors receive inaccurate information less. It should be pointed out that the social network administrators of Glacier National Park received positive reviews from site visitors, since the way they communicate with them is extremely friendly (https://www.ntc. blm.gov/krc).

The data collected from social media can be used as a valuable source to understand visitors' preferences for nature-based experiences in protected areas (Hausmann et al., 2017). Hausmann and colleagues (2017) point out that there is no significant difference between the preferences of tourists as it is stated in the traditional surveys and the preferences revealed by social media content they examined in Kruger National Park, South Africa. Based on this research, it has also been determined that several different social media provide a better basis for the recognition of tourist expectations in ecotourism. This basis also enables the monitoring of the activities of the eco-tourists at the destination. The fact is that the way a social media is used is not the same for all eco-tourists. First of all, the choice of social media varies according to the age of the eco-tourists, but also by how much they are attached to nature or some other activities in nature. The way data is received through social networks can be a good step towards fully familiarizing expectations of eco-tourists in order to provide them with a better experience at the destination. The job of the manager on the protection of natural resources can be made easier, at least as far as the behaviour of the eco-tourists at the destination is concerned. It can bring out the implementation of adequate protection strategies for such areas, e.g., national parks. By analysing tourist's location, through social media, it is possible to see where tourists mostly travel and whether the protected areas are endangered, as well as certain animal species.

With the use of social networks, it is possible to create a good image with investors, states, volunteers and employees. It is therefore important that national parks do not base their communication via email, in addition to social media that are responsible for informing visitors and the public (Garrison, Li, 2014).

According to a survey carried out by Garrison and $\mathrm{Li}$ (2014) in national parks in the United States, most national parks use social media in communication with visitors. The largest number of NP use the Facebook as social network, but there is a difference between the degree of use among parks. Next are Twitter and Flickr with a little bit of presence, then YouTube, while blogs are used to the minimum. 


\section{Methodology}

\section{Quantifying elements of Facebook Pages}

The proposed approach used for data gathering is based on a systematic processing of meaningful and open selection of variables, with technically low-demanding procedures usually used in research of destination management organizations. Based on the review of the contemporary studies of Facebook and advances in Facebook usability variables were chosen. These characteristics are not conclusive, but they are offered to spark consideration and to add to the constantly open debate which is necessary concerning the dynamic nature of this social medium.

In general, Facebook Pages were analyzed in terms of general usage and Page popularity. In addition, within a selected timeframe, all published Facebook Page posts were analyzed in terms of post characteristics and user's engagement.

The research is based on explanation of some basic characteristics of Pages and posts that should be considered. When visiting a Page, if the user has not landed from an official NP's website, there is always a question of Page authenticity. Simple Google search or search using Facebook internal search engine will often results in various unofficial Pages (Dwivedi et al. 2011). Individuals and groups often create fan or commercial pages which are related to the geographical areas that are already designated as NP. This can confuse the users. Therefore, complete authenticity can be guaranteed by Facebook when Page is manually verified with assignation of special verification sign next to Page's title (Facebook Developers 2015b).

The structure of Facebook Pages can be enriched by using standard or created Page Tabs. Facebook Page is actually a separate web page containing different content. Besides standard Facebook Tabs, such as ("About", "Photos", "Videos", etc) businesses can make custom Tabs containing different types of apps, welcoming messages, polls, showcase videos, reservation forms, etc. Generally, custom Facebook Tabs can create a much richer user experience and add value to the standard Facebook Page (Pitre, 2015). If business pays attention merely to the main Page News Feed (Page Wall) it can be considered as neglecting and limiting the full potential of this SNS for spreading of the information and collaboration with the users (Hsu 2012; Zouganeli et al. 2011).

Frequent posting provides new content, keeps members engaged and allows greater interaction with the fans (Zarrella, Zarrella 2010). However, high posting frequency does not necessary guarantee high engagement rates. For example, the study of Mariani and colleagues (2016) for the regional DMOs in Italy found that high post frequency has a negative impact on user's engagement.

Facebook users' personal news feed (i.e. Walls) are constantly filled with content coming from multiple sources (other users' profiles, Facebook Pages liked by users, sponsored content). On average, only about $17 \%$ of a business Page's post shows up on fans' walls (Hubspot 2015). Facebook uses complex ranking algorithm based on machine learning to select and rank the content that shows up in the user's news feed.

\section{Data gathering and methods}

The data collections were gathered in two ways. The data for Pages were collected manually and using the customized requests, based on the Graph API Explorer. Facebook's Social Graph is a graph data structure that represents social interaction and consists of nodes and connec- 
tions between the nodes (Russell, 2013). The authors used Graph API Explorer v2.4 to query information, such as the number of users who like the Page.

For those information when automated approach was restricted by Facebook privacy policy (such as number of tabs), authors used manual data gathering.The data for Page posts was gathered automatically using page data module of Netvizz v1.25 tool. This Facebook tool extracts data from different sections of the Facebook groups and pages (Rieder, 2013). Extracted data included information on Facebook's post classification).

\section{Results}

\section{The extent of presence on Facebook and Page characteristic}

A survey of Facebook Pages managed by former Yugoslav NP showed 100\% presence in case of Bosnia and Herzegovina, Croatia, FYR Macedonia and Serbia. NPs from Montenegro are not included in the analysis as they had joint Facebook Page managed by the authority managed on the national level. The only NP in Slovenia did not have an official Facebook Page at the moment of analysis (see Table 1).

Table 1. Number of NP Facebook Pages in former Yugoslav countries up to May 1st, 2016.

\begin{tabular}{|l|c|c|}
\hline Country & Number of NPs & Number of FB Pages \\
\hline Bosnia and Herzegovina & 3 & 3 \\
\hline Croatia & 8 & 8 \\
\hline FYR Macedonia & 3 & 3 \\
\hline Montenegro & 5 & 1 \\
\hline Serbia & 5 & 5 \\
\hline Slovenia & 1 & 0 \\
\hline
\end{tabular}

Source: Survey conducted by authors

Most Facebook Pages are created in 2012 and 2013. First NP Facebook Page in the region dates from 2008, and two new ones are created in 2016.

Table 2. Average number of Tabs and Fans per NP Facebook Pages

\begin{tabular}{|l|c|c|}
\hline Country & Average no. of Tabs & Average no. of Fans \\
\hline Bosnia and Herzegovina & 7,3 & 4,124 \\
\hline Croatia & 9 & 17,505 \\
\hline FYR Macedonia & 6,6 & 1,950 \\
\hline Serbia & 6,8 & 7,628 \\
\hline
\end{tabular}

Source: Survey conducted by authors

Pages are very similar in terms of Tab (around 7) with the exception of Croatia with 9 Tabs. As mentioned above, Tabs can highly increase the attractiveness of standardized Page structures.

In average, Pages of NP from Croatia had significantly higher number of Fans, while FYR Macedonia recorded the lowest number. 


\section{Characteristics of Facebook Page's posts}

Average number of posts per Page showed that Croatian NPs are the most active. NP from Bosnia and Herzegovina and Serbia post similar average number of messages, while least active are NP from FYR Macedonia (Table 3).

Table 3. Monthly average of Facebook posts published by NP and average engagement per posts

\begin{tabular}{|l|c|c|}
\hline Country & $\begin{array}{c}\text { Monthly average of } \\
\text { posts }\end{array}$ & $\begin{array}{c}\text { Average engagement } \\
\text { per post }\end{array}$ \\
\hline Bosnia and Herzegovina & 38.5 & 72.2 \\
\hline Croatia & 132.3 & 188.7 \\
\hline FYR Macedonia & 7.3 & 52.7 \\
\hline Serbia & 35.5 & 125.9 \\
\hline
\end{tabular}

Source: Survey conducted by authors

Facebook users exhibit the highest level of engagement with posts published by NP from Croatia. Although NPs from Bosnia and Herzegovina and Serbia post similar number of messages, Facebook users engaged significantly more with posts form Serbia. Again, NPs from FYR Macedonia averagely received the lowest level of users' engagement.

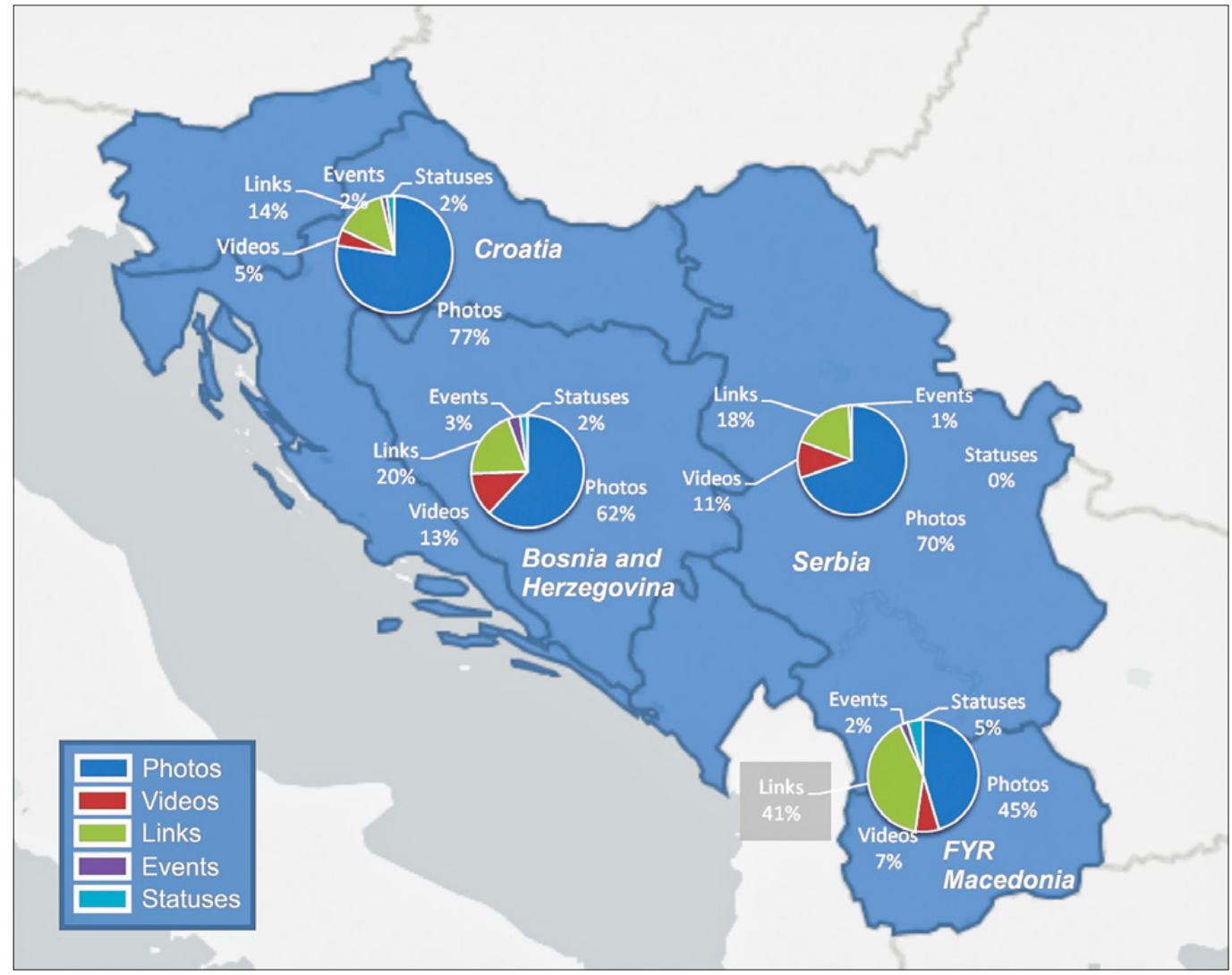

Figure 1. The structure of NP Facebook page posts based on the type of content Source: Provided by authors 
The structure of NP Facebook page posts based on the type of content presented in the Figure 1, clearly point out that photographs are the dominant type of content. Croatian and Serbian NPs post photos most frequently. It is followed by NPs from Bosnia and Herzegovina. After photographs, links are the second common type of posts. NPs from FYR use the higher level of links among all other former Yugoslav countries. This goes on the expense of the ration of photographs preferred in other countries. Videos received the third place in the structure of page posts, while events and statuses are least common type in all of these countries.

\section{Conclusions}

This study aimed to examine the similarities and differences in adopting and current practices of Facebook usage by the NPs in former Yugoslav countries. Preliminary results show that NPs in this region recognized Facebook as a communication channel, but still have problems in realizing how to use it, that is, how to find effective strategies for managing existing Pages.

Based on the results, it can be noticed that Croatia is the most successful in managing Facebook pages of national parks, compared to other survey countries, as evidenced by the number of tags and the number of posts. This should also include the number of users i.e. fans and their engagement on the pages. These results can be explained by the fact that Croatia has the most developed tourism market in comparison with the analyzed countries. By the same criteria, Serbia is in second place, and Bosnia and Herzegovina on the third. National parks from FYR Macedonia have the worst ranking results or the lowest presence and engagement on Facebook.

This paper demonstrates applicability of common methodology used for assessing DMO Facebook Pages in case of NPs. Furthermore, the results provide valuable insights into the regional practice of using Facebook Pages in former Yugoslav countries. The approach employed stresses the importance of determination of NP Facebook practice in regional settings by pointing out structural problems. In that sense, knowledge of the common Facebook usage standards can help NPs to evaluate their position in the region and adjust their practice. The current trend is to "push" information to online users and provides an additional dynamic view of the users. Using social network sites allow travellers to interact directly with each other, since, for example Facebook allows for the creation of group and fan pages. On the other side, the use of social media by the NPs needs to be intently planned in order to understand the type of information visitors would like to receive and the best way to facilitate communication with them.

The findings of this paper could contribute to the existing research of the use of SNSs by NPs, specifically Facebook, by giving them guidelines for establishing good practice. Finally, data from social networks should not be taken for granted. These data should be supported by traditional research or compared with other surveys.

\section{References}

Baltas, G. 2003. Determinants of internet advertising effectiveness: an empirical study. International Journal of Market Research 45, 505-514.

Belanche, D., Casalo, L.V., Flavian, C., Guinaliu, M. 2010. Online social networks in the travel sector. International Journal of Electronic Marketing and Retailing 3, 321-340. 
Chung, J. Y., Buhalis, D. 2008. Information needs in online social networks. Information Technology \& Tourism 10(4), 267-281.

Cooper, A. (2010), "Facebook", [online]. Available at: http://drcoop.pbworks.com/w/ page/18221293/Facebook (Accessed 10.02.2015).

Cooper, A., 2010. Facebook. PBworks. Available online: http://drcoop.pbworks.com/w/ page/18221293/Facebook (Accessed 09.03.2015).

Dwivedi, M., Yadav, A., Venkatesh, U. 2011. Use of social media by national tourism organizations: a preliminary analysis. Information Technology \& Tourism 13, 93-103.

Eisenberg, B., Eisenberg, J. 20o6. Call to Action: Secret Formulas to Improve Online Results. Thomas Nelson, Nashville.

Facebook Developers 2015a. Graph API Overview. Facebook Developers. Available online: https://developers.facebook.com/docs/graph-api/overview (10.06.2015).

Facebook Developers 2015b. Page. Facebook Developers. Available online: https://developers. facebook.com/docs/graph-api/reference/page (10.06.2015).

Fotis, J., Buhalis, D., Rossides, N. (2012). Social media use and impact during the holiday travel planning process, 19th international conference on information and communication technologies in travel and tourism. Helsingborg, Sweden.

Garrison, B. and Li, Z. (2014). Communication from a Federal Agency: A Case Study of Social Media Use and Policy. Public Relations Division, National Communication Association annual conference. Chicago, Ill.

Gretzel, U, Yoo, K.H., Purifoy, M. 2007. Online travel review study: role and impact of online travel reviews, Laboratory for Intelligent Systems in Tourism, Texas A \& M University. Available online: www.tripadvisor.com/pdfs/OnlineTravelReviewReport.pdf (10.06.2017).

Hsu, Y.L. 2012. Facebook as international eMarketing strategy of Taiwan hotels. International Journal of Hospitality Management 31, 972-980.

Hubspot. 2015. How to engage fans on Facebook. Hubspot. Available online: http://cdn1.hubspot.com/hub/53/How-to-Engage-Fans-on-Facebook-04.pdf (11.03.2017).

Linnell, N. 2012. How to Analyze Facebook Page Posts. Search Engine Watch. Available online: https://searchenginewatch.com/sew/how-to/2206120/how-to-analyze-facebook-pageposts (10.02.2015).

Mariani, M.M., Di Felice, M., Mura, M. 2016. Facebook as a destination marketing tool: Evidence from Italian regional Destination Management Organizations. Tourism Management 54, 321-343

Matloka, J., Buhalis, D. (2010). Destination marketing through user personalised content (UPC). International Conference on Information and Communication Technologies in Tourism. Lugano, Switzerland.

Pempek, T. A., Yermolayeva, Y. A., Calvert, S. L. 2009. College students' social networking experiences on Facebook. Journal of applied developmental psychology 30(3), 227-238.

Pitre, A. 2015. How to Create Custom Tabs for Your Facebook Business Page. Hubspot. Available online: http://blog.hubspot.com/blog/tabid/6307/bid/26330/How-to-Create-CustomTabs-for-Facebook-Business-Pages.aspx (10.04.2017).

Rieder, B. (2013). Studying Facebook via data extraction: the Netvizz application". WebSci '13 Proceedings of the 5th Annual ACM Web Science Conference, (346-355). ACM, New York.

Russell, M.A. 2013. Mining the Social Web: Data Mining Facebook, Twitter, LinkedIn, Google+, GitHub, and More. O'Reilly Media,Sevastopol.

Tham, A. G. J. 2013. Social media in destination choice: Distinctive electronic word-ofmouth dimensions. Journal of Travel E Tourism Marketing 30(1/2), 144. 
Stankov, U., Jovanović, T., Pavluković, V., Kalinić, Č., Drakulić-Kovačević, N., Cimbaljević, N. 2018. A regional survey of current practices on destination marketing organizations' Facebook Pages: the case of EU and U.S. Geographica Pannonica, in press. postoji DOI!!!

Tenkanen, H., Di Minin, E., Heikinheimo, V., Hausmann, A., Herbst, M., Kajala. L., Toivonen, T. 2017. Instagram, Flickr,or Twitter: Assessing the usability of social media data for vistor monitoring in protected areas. Scinetific Reports, 7(1), in press.

Zarrella, D., Zarrella, A. 2010. The Facebook marketing book. O'Reilly Media, Sebastopol.

Zouganeli, S., Trihas, N., Antonaki, M. 2011. Social media and tourism: the use of Facebook by the European national tourism organizations. Tourism Today 11, 110-121.

\section{\|\|\|\|}

Internet 1: https://www.ntc.blm.gov/krc/uploads/412/14a_MbN_GlacierNP_social-media-mgmt-plan_draft.pdf

Internet 2: https://www.cabi.org/leisuretourism/news/64986 